\title{
Evidence of increased substrate availability to in vitro-derived bovine foetuses and association with accelerated conceptus growth
}

\author{
M Bertolini, A L Moyer, J B Mason, C A Batchelder, K A Hoffert, L R Bertolini, G F Carneiro", \\ S L Cargill, T R Famula, C C Calvert, R D Sainz and G B Anderson \\ Department of Animal Science and ${ }^{1}$ Department of Population Health and Reproduction, University of California, \\ Davis, CA, USA
}

Correspondence should be addressed to G B Anderson; Email: gbanderson@ucdavis.edu

\begin{abstract}
Changes in placental development have been associated with foetal abnormalities after in vitro embryo manipulations. This study was designed to investigate bovine conceptus development and substrate levels in plasma and fluids in in vivo- and in vitro-produced (IVP) concepti and neonates. In vivo-produced and IVP embryos were derived by established embryo production procedures. Pregnant animals from both groups were slaughtered on days 90 or 180 of gestation, or allowed to go to term. Conceptus and neonatal physical traits were recorded; foetal, maternal and neonatal blood, and foetal fluids were collected for the determination of blood and fluid chemistry, and glucose, fructose and lactate concentrations. Placental transcripts for specific glucose transporters were determined by quantitative RT-PCR. No significant differences in uterine and conceptus traits were observed between groups on day 90. On day 180, larger uterine, placental and foetal weights, and an increase in placental gross surface area (SA) in IVP pregnancies were associated with increased glucose and fructose accumulation in foetal plasma and associated fluids, with no differences in the expression of components of the glucose transporter system. Therefore, the enlarged placental SA in IVP pregnancies suggests an increase in substrate uptake and transport capacity. Newborn IVP calves displayed higher birth weights and plasma fructose concentrations soon after birth, findings which appeared to be associated with clinical and metabolic distress. Our results indicated larger concepti and increased placental fructogenic capacity in mid- to late IVP pregnancies, features which appeared to be associated with an enhanced substrate supply, potentially glucose, to the conceptus.

Reproduction (2004) 128 341-354
\end{abstract}

\section{Introduction}

Birth weight is an important determinant of perinatal outcome, and oversized calves are a major cause of neonatal mortality in cattle (Ferrell 1989). With development of in vitro embryo production systems, such as in vitro fertilization (IVF) and nuclear transfer (NT) procedures, pre- and postnatal abnormalities have appeared, such as excessive birth weights with reduced neonatal survival in calves (Willadsen et al. 1991, Behboodi et al. 1995, Farin \& Farin 1995, Walker et al. 1996, Farin et al. 2001, Bertolini \& Anderson 2002). Abnormal placental development and function have also been associated with in vitro embryo manipulations, with alterations causing increases in pregnancy failure and abnormal prenatal growth (Hasler et al. 1995, Stice et al. 1996, Hill et al. 2000, 2001, Bertolini et al. 2002b, Hashizume et al. 2002). The placenta is virtually the sole interface responsible for the exchanges between the foetal and maternal systems; all substrates required for foetoplacental growth and development originate from the maternal system, and the amounts of substrates that reach the foetus are transported, metabolized or modified by the placenta. Disturbances in placentation and placental function may lead to changes in the pattern of foetal growth (Schlafer et al. 2000), corroborating findings that abnormal placentation is associated with foetal abnormalities after in vitro embryo manipulations (Hill et al. 2000, Bertolini et al. 2002b, Hashizume et al. 2002).

Most metabolites supplied to the placenta are metabolized or modified by placental tissue, with glucose being the major substrate required for conceptus metabolic demands during pregnancy in cattle (Ferrell 1989, Ferrell \& Reynolds 1992). At the placental level, the glucose transporters Glut- 1 and -3 are responsible for the transmembranal transport of glucose down its concentration gradient. It has been hypothesized that, during the course 
of pregnancy, Glut-1 is important for glucose uptake for placental utilization, whereas Glut-3 may be linked to foetal glucose transfer (Ehrhardt \& Bell 1997). Fructose, the predominant reducing sugar present in foetal plasma and foetal fluids in cattle (Goodwin 1956, Hugget \& Nixon 1961, Nixon 1963), is transported in mammalian cells by Glut- 5 and supposedly by other novel members of the glucose transporter family (Girniene et al. 2003). The placental fructogenic activity appears to be dependent on glucose supply to the uteroplacental tissue (Aldoretta \& Hay 1999), but evidence demonstrating the importance of fructose transporters at the bovine placenta is lacking.

Essential differences exist between the metabolism of glucose and fructose. Regulatory key metabolic enzymes and hormonal actions such as insulin strictly control glucose homeostasis and metabolism, whereas fructose metabolism, which is not under hormonal control, is more unpredictable (Froesch 1976). Fructose bypasses the regulatory step catalysed by phosphofructokinase in the liver, undergoing a more rapid breakdown than glucose, and increasing the provision of substrates in all downstream metabolic pathways (Mayes 1993). Consequently, excessive plasma fructose concentrations may profoundly affect carbohydrate and lipid metabolism, even causing lactic acidosis under certain conditions (Mayes 1993, Van den Berghe 1994). Neonates may experience a transient period of metabolic acidosis soon after birth due to hypoxia caused by respiratory distress (Seri 1998). However, it is possible that the presence of pregnancy-derived higher fructose levels in the plasma of newborn calves may be metabolically and clinically beneficial for postnatal adaptation to life ex utero, but deviations from physiological normality (as in systemic hypoxia caused by neonatal respiratory distress) may cause profound metabolic consequences, such as lactic acidosis, that might compromise postnatal survival.

A placental-cause and foetal-effect hypothesis has been suggested (Bell et al. 1999) in which the degree of constraint or compliance in the nutrient supply to foetuses in late gestation may be associated with the pattern of placental growth occurring during early and mid-pregnancy (Bell et al. 1999, Symonds et al. 2001). The concept of maternal and placental constraint involves a physiological homeostatic mechanism that ensures maternal survival (Ferrell 1991 a,b, Gluckman et al. 1992), and is related to the control of nutrient supply to foetuses in late gestation (Gluckman et al. 1992). We observed previously that high birth weights following in vitro embryo manipulations are associated with early conceptus growth restriction and aberrant placentation (Bertolini \& Anderson 2002, Bertolini et al. 2002b). Accelerated prenatal growth appears to be due to an increase in maternofoetal substrate net flow rates in late in vitro-produced (IVP) pregnancies in the last trimester of pregnancy. This study was designed to investigate the relationship between deviations in foetal growth and neonatal well-being, and substrate supply and availability to the conceptus during pregnancy after in vitro embryo manipulation. To address such associations, we utilized an in vitro production system known to induce at a relatively high frequency the manifestation of symptoms of the large calf syndrome during the course of pregnancy, as described in our previous reports (Behboodi et al. 1995, Bertolini \& Anderson 2002, Bertolini et al. 2002b).

\section{Materials and Methods}

Pregnancies for IVP and in vivo control embryos were either slaughtered on days 90 or 180 of gestation (experiment 1) or allowed to proceed to term (experiment 2). Foetal growth and placental morphology and function in IVP versus control concepti and newborn calves were compared.

\section{Bovine embryo production and transfer, pregnancy and foetal gender diagnoses}

\section{In vitro embryo production}

In experiment 1 , cumulus-oocyte complexes (COC) from Bos taurus slaughterhouse ovaries (Angus-Hereford-cross females) were obtained from a commercial source (Biomed Inc., Madison, WI, USA; www.bomed.com/bomed3.html). In experiment 2, B. taurus ovaries were collected from Angus-Hereford-cross females in a regional slaughterhouse, isothermically transported to the laboratory and processed as described by Bertolini et al. $(2002 a, b)$. In vitro maturation (IVM), in vitro sperm capacitation and IVF were performed according to our established procedures (Bertolini et al. 2002a,b). Upon completion of IVM (20$24 \mathrm{~h}$ ), COC and sperm cells were co-incubated in IVFTALP medium for $18-20 \mathrm{~h}$. Groups of 50 cumulus-free presumptive zygotes were co-cultured in organ culture dishes, along with bovine oviductal epithelial cells (BOEC), for 7 days to the blastocyst stage, as described previously (Bertolini et al. 2002a,b). During in vitro culture, culture medium was partially replaced on days 1 and 5 after fertilization $(\mathrm{IVF}=$ day 0$)$ by the removal, and subsequent replacement, of approximately $50 \%$ of its volume. All incubations were conducted at $39^{\circ} \mathrm{C}, 5 \% \mathrm{CO}_{2}$, in humidified air, and all gamete and embryo manipulations took place in a temperature-controlled room $\left(30-32^{\circ} \mathrm{C}\right)$. Chemicals used in the experiments were from Sigma Chemical Co. (St Louis, MO, USA), unless stated otherwise.

\section{In vivo embryo production}

Control embryos were obtained after superovulation and artificial insemination (Al) of donor females (Angus or Angus-Hereford crosses) for both experimental groups, as described elsewhere (Bertolini et al. 2002a,b). Oestrous cycles of donors and recipients were synchronized, and a total of 36-44 U of FSH-p (Oocyte Media Supplement, Sioux Biochemical, Sioux Center, IA, USA) was given i.m. to the donors, in decreasing doses, twice a day, for 4 consecutive days, starting on day 9 or 10 of the oestrous 
cycle. A dose of prostaglandin (PG) $\mathrm{F}_{2 \alpha}$ was injected i.m. into the donors along with the sixth and seventh injections of FSH-p. Oestrus detection was performed every $4-6 \mathrm{~h}$, and $\mathrm{Al}$ was performed at $10-12$ and $22-24 \mathrm{~h}$ after the onset of oestrus. On day 7 of development $(\mathrm{Al}=$ day 0$)$, embryos were nonsurgically recovered by uterine flushing.

The same Angus sire was used for the production of both control and IVP embryos for experiment 1 (expected progeny difference (EPD) for birth weight of $-0.86 \mathrm{~kg}$, 0.99 accuracy), and experiment 2 (EPD for birth weight of $+1.00 \mathrm{~kg}, 0.99$ accuracy). All animals were from a similar genetic background (Angus or Angus-Hereford crosses) and origin, and animals in each experiment were maintained under the same environmental, nutritional and general management conditions for the entire period of the experiments. Animal use and procedures conformed to the Guidelines for Care and Use of Laboratory Animals, National Research Council, and were approved by the Animal Care and Use Committee of the University of California, Davis.

\section{Embryo transfer and pregnancy and gender diagnoses}

Day-7 control and IVP blastocysts and expanded blastocysts were nonsurgically transferred (ET) to recipients synchronously $( \pm 12 \mathrm{~h})$ to the donors. In experiment 1 , pregnancy and foetal gender diagnoses were carried out by means of ultrasonography, per rectum, on days 27 and 60 of gestation respectively, or, as described by Bertolini et al. (2002b), for experiment 2, by real-time, B-mode veterinary portable ultrasound scanner (Aloka SSD-500V; Aloka Co. Ltd, Wallingford, CT, USA) equipped with a $5 \mathrm{MHz}$ linear-array transducer.

\section{Experiment 1: conceptus development on days 90 and 180 of gestation}

After a fasting period of $12 \mathrm{~h}$, pregnant females $(n=18)$ from each experimental group $(n=4$ in control and $n=5$ IVP pregnancies for each day) were slaughtered on days 90 and 180 of gestation for the collection of the pregnant uteri and their respective foetuses and placentas. Maternal blood samples were obtained at the time of exsanguination; reproductive tracts were excised, weighed and dissected along the greater curvature. Total allantoic and amniotic fluid volumes were measured and sampled. The umbilical cord was clamped and excised, and the foetus was removed and weighed. Foetal blood was collected by cardiopuncture while the foetal heart was, in most foetuses, still beating. Maternal and foetal blood, and amniotic and allantoic fluids were centrifuged and stored at $-80^{\circ} \mathrm{C}$ pending analyses. Substrate (glucose, fructose and lactate) concentrations were determined in plasma and fluids. Foetal fluid physicochemistry were also measured, as described below. Foetal physical measurements (body weight, crown-rump and crownnose lengths, limb lengths, humeral and femoral lengths, and heart girth circumference), and tissue (skeletal muscles: supraspinatus, longisimus dorsi, semitendinosus and biceps femoris), organ (heart, lungs, brain, kidneys, liver, spleen, thymus, gastrointestinal tract and gonads) and endocrine gland (thyroid, pituitary and adrenals) weights were recorded. Individual placentomes were excised from the uterus, weighed and physically measured (length and width) for the estimation of the total gross surface area (SA). Foetal membranes and uterine tissues were inspected and morphological abnormalities recorded. Sample placentomes from the region surrounding the foetuses were excised in their longitudinal axis, and pieces containing both maternal and foetal boundaries were snap-frozen in liquid nitrogen, stored at $-80^{\circ} \mathrm{C}$ and used for the measurement of the relative transcription of component genes of the glucose transporter system (Glut-1, -3 and -5 ).

\section{Experiment 2: clinical and physiological characteristics of neonates}

The morphometric and morphological data regarding foetal and placental developments during pregnancy and after delivery for the group of recipients allowed to carry pregnancies to term have been previously described in detail (Bertolini et al. 2002b). Periparturient females were allocated to individual pens and observed every $3-4 \mathrm{~h}$ for signs of labour. Upon delivery, neonates were clinically assisted when necessary (mostly oxygen therapy). Birth weight before colostrum intake and physical traits were recorded, and foetal membranes (FM) were weighed, dissected, morphologically inspected and measured upon expulsion, as previously reported (Bertolini et al. 2002b). After calving, neonatal venous blood samples were collected by jugular venipuncture within the first $10 \mathrm{~min}$, a procedure which should reflect intrauterine conditions for several blood measurements, and at 1, 6, 12 and $24 \mathrm{~h}$ after birth. For each collection time, one set of blood samples was drawn in heparinized syringes and snapcooled to $0^{\circ} \mathrm{C}$ upon collection, to be sent immediately for blood chemical analyses, and another set was taken in heparinized tubes. Upon collection, blood samples in tubes were immediately centrifuged, and plasma was frozen at $-80^{\circ} \mathrm{C}$ pending analyses. Basic clinical signs (rectal temperature, respiratory rate and heart rate), blood physicochemistry and plasma substrates were observed and/or measured for each newborn at all five postnatal times, as described below. Only data representing pregnancies that delivered singleton calves from both experimental groups are presented.

\section{$D$-Glucose, D-fructose and L-lactate measurements in plasma and foetal fluids}

Concentrations of glucose, fructose and lactate were determined in duplicate in the maternal, foetal and neonatal plasma, and in foetal fluids by colorimetric assays. Glucose concentrations were determined with a glucose (Trinder) assay kit (Sigma Diagnostics, St Louis, 
MO, USA), according to the manufacturer's recommendations. The colorimetric fructose analysis of Taylor (1995) was employed for the quantification of D-fructose in the samples (maternal, foetal and neonatal plasma, and amniotic and allantoic fluids), with minor modifications. Due to elevated fructose concentrations in the foetal plasma and amniotic and allantoic fluids, samples were diluted in distilled deionized water, prior to the analysis, by a factor of 1:4 (foetal plasma and amniotic fluid) and 1:10 (allantoic fluid). Lactate concentrations were determined with a lactate assay kit (Sigma Diagnostics), according to the manufacturer's recommendations. Absorbance (A) was measured in a preset spectrophotometer (UV-160 A recording spectrophotometer; Shimadzu Co., Analytical Instruments Division, Kyoto, Japan). Intra- and interassay variations were $3.7-6.9 \%, 4.1-10.5 \%$ and $0.1-4.9 \%$ for the glucose, fructose and lactate assays respectively.

\section{Blood and fluid physicochemistry}

\section{Amniotic and allantoic fluid chemistry}

Electrolyte concentrations $\left(\mathrm{Na}^{+}, \mathrm{K}^{+}\right.$and $\left.\mathrm{Cl}^{-}\right)$, creatinine concentrations, total fluid protein and osmolarity (experiment 1) were analysed in the amniotic and allantoic fluids by the indirect ion selective electrode (ISE) method (electrolytes) and the modified Jaffe method (creatinine), both on a Hitachi 717 analyser (Roche Diagnostics, Indianapolis, IN, USA), by the microprotein method using the pyrogallol red reagent (Sigma), and by an osmometer (Osmette $A$ Automatic Osmometer; Precision Systems, Inc., Natick, MA, USA) respectively.

\section{Neonatal blood chemistry}

Whole blood samples collected in heparinized syringes (experiment 2) were analysed for blood gases $\left(\mathrm{pCO}_{2}\right.$ and $\mathrm{pO}_{2}$ ), acid-base status ( $\mathrm{pH}$ and $\mathrm{HCO}_{3}^{-}$) and electrolyte concentrations $\left(\mathrm{Na}^{+}, \mathrm{K}^{+}, \mathrm{Cl}^{-}\right.$and $\left.\mathrm{Ca}^{2+}\right)$ in an automatic blood gas/electrolyte analyser (Radiometer ABL505; Radiometer
America, Westlake, OH, USA). Packed cell volume (PCV) and total plasma protein (TPP) were determined after blood capillary centrifugation and refractometry respectively.

\section{Relative transcriptional activity of glucose transporter genes in day-90 and day-180 placentomes}

A real-time TaqMan PCR was utilized to quantify transcripts for Glut-1, -3 and -5 genes, by procedures described by Bertolini et al. (2002 b). Quantitative analyses of bovine cDNA from control and IVP day-90 and day-180 placentomes were performed in comparison to the endogenous control (glyceraldehyde-3-phosphate dehydrogenase (GAPDH)), and were amplified in an automated laser-based fluorometer (7700 ABI PRISM Sequence Detection System, Applied Biosystems). Final quantification was accomplished by the comparative $\mathrm{C}_{\mathrm{T}}$ method (Leutenegger et al. 2000). All samples were included in each TaqMan assay; one assay was run per transcript, in single reactions. Ten parallel reactions were run with the same cDNA and in 10 independent assays to determine the intra-assay and interassay variations respectively. Sequences of PCR primers, TaqMan probes and GenBank accession code numbers for the transcripts are shown in Table 1.

\section{Statistical analyses}

Data analyses were conducted with Proc GLM of SAS (SAS Institute, Cary, NC, USA). Data obtained in experiment 1 were compared by ANOVA, considering group (in vivo, in vitro), day (90 and 180) and gender (male and female) as main effects. Data were also compared by ANCOVA, using foetal weight as the covariate. Qualitative data and distribution of placentome size were analysed by the Kruskal-Wallis test (Minitab, State College, PA, USA). Data in experiment 2 were analysed by the repeated measures procedures of SAS (group and time as main effects with animal nested within group). Pairwise comparisons were performed by least square means (LSM). Pearson's correlation test was used for the analysis of

Table 1 Sequence of PCR primers, TaqMan probes and GenBank accession code numbers for the transcripts analysed in B. taurus control and IVP day-90 and day-180 placentomes.

\begin{tabular}{|c|c|c|c|c|}
\hline Transcripts & Primer sequences $\left(5^{\prime}-3^{\prime}\right)^{\mathrm{a}, \mathrm{b}}$ & Length & Probe sequences $\left(5^{\prime}-3^{\prime}\right)^{\mathrm{b}}$ & Accession no. \\
\hline GAPDH & $\begin{array}{l}\text { F-GGGCGTGAACCACGAGAAGTATAA } \\
\text { R-CCCTCCACGATGCCAAAGT }\end{array}$ & 120 & $\begin{array}{l}\text { ATACCCTCAAGATTGT } \\
\text { CAGCAATGCCTCCT }\end{array}$ & AF022183 \\
\hline Glut-1 & $\begin{array}{l}\text { F-CCACCAGCAAGAAGCTGACA } \\
\text { R-GCTGGACCCACGTCTGGTT }\end{array}$ & 144 & $\begin{array}{l}\text { TTGGCTACAACACTGG } \\
\text { AGTCATCAACGC }\end{array}$ & M60448 \\
\hline Glut-3 & $\begin{array}{l}\text { F-GGGTGGTATGATTGGTTCCTTC } \\
\text { R-AAGGCAGCCGCCAGCTAT }\end{array}$ & 106 & $\begin{array}{l}\text { CGATTTGGCAG } \\
\underline{G C G C A A C T C A \overline{A T}}\end{array}$ & L39214 \\
\hline Glut-5 & $\begin{array}{l}\text { F-GCGCTATTTTCGTGGTGGAA } \\
\text { R-CGCAGCAAGCGGTGAGA }\end{array}$ & 81 & $\begin{array}{l}\text { ССТGСТССТССТGGGСTTCT } \\
\text { СTGTC }\end{array}$ & AF308830 \\
\hline
\end{tabular}

${ }^{\text {a }}$ Primer orientations: F-forward; R-reverse.

${ }^{\mathrm{b}}$ Exon-exon junctions are underlined in the probes for GAPDH, Glut-1 and Glut-3, and in the forward primer for Glut-5. 
relationships between traits in both experiments, also using values corrected for the covariate, as well as the other fixed effects of group, time and animal.

\section{Results}

\section{Pregnancy rate, losses and foetal gender diagnosis}

Considering both experiments combined, no differences were observed between groups in both pregnancy rates (20/53 and 36/112 for the control and IVP groups respectively) and occurrence of losses after day 45 of gestation (2/20 and 3/36 for the control and IVP groups respectively), but losses between days 30 and 44 of gestation were 3.4 -fold higher $(P<0.05)$ in the IVP group $(17 / 36)$ than in controls $(4 / 20)$. In experiment 1 , pregnancy rates on day 27 were $33 \%(10 / 30)$ and $32 \%$ (27/84), for the control and IVP groups respectively, and pregnancy losses from day 27 of gestation (pregnancy diagnosis) to day 60 (foetal gender diagnosis) were $10 \%$ $(1 / 10)$ and $63 \%(17 / 27)$ respectively. Two control pregnancies were lost, one before day 45 and the other on day 160 of gestation. In the IVP group, $82 \%$ (14/17) of the losses occurred before day 45 of gestation, with the remainder of the losses taking place between days 45 and 60 of gestation (3/17). The diagnosis of foetal gender by ultrasonography indicated that the IVP group contained seven females and four males (including a dead foetus on day 55), and the control group had seven females (including the aborted female foetus on day 160) and two males. Pregnant females were allocated to each harvest day according to foetal gender and foetal viability. In the control group $(n=8)$, animals carrying three females and one male were assigned to each harvest day (90 and 180), and in the IVP group $(n=10)$, female recipients sustaining pregnancies with four females and one male were harvested on day 90, and recipients carrying three females and two males on day 180 of gestation. Foetal gender diagnoses performed on day 60 of pregnancy were all confirmed after harvest. Results regarding the pregnancy rate, losses and foetal gender diagnosis in experiment 2 have already been reported (Bertolini et al. 2002b).

\section{Conceptus growth and development on days 90 and 180 of gestation}

Linear measurements of conceptus physical traits for controls and IVP pregnancies on days 90 and 180 of gestation demonstrated proportionality between foetal body size and body weight, with no physical deformities observed in any foetus. Overall, IVP conceptus traits tended to be heavier and larger than controls, but, as male foetuses were also heavier and larger, differences between groups were not as pronounced due to the low occurrence and inclusion of male concepti in both groups. Consequently, data analyses were also carried out only for females, by exclusion of males from each group (Table 2). Uterine, placental and foetal physical traits on day 90 were similar between groups, irrespective of the inclusion or exclusion of males in the analyses.

Except for individual placentome sizes, which were longer, wider and thinner in the IVP group, no other significant physical differences in uterine and conceptus (foetus and placenta) traits were observed on day 90 between IVP and control groups. However, differences in uterine (genital tract weight) and foetal traits between groups were more pronounced on day 180 of gestation, irrespective of the foetal gender (Table 2). Foetal livers, hearts, kidneys, longisimus dorsi muscles $(81.65 \pm 12.97 \mathrm{~g}$ vs $56.12 \pm 10.73 \mathrm{~g})$ and thyroids $(3.91 \pm 0.81 \mathrm{~g}$ vs $2.58 \pm 0.24 \mathrm{~g}$ ) were heavier, brains lighter and femurs longer in day-180 IVP foetuses than in controls respectively $(P<0.05)$. The empty reproductive tracts in the IVP group were significantly heavier $(P<0.05)$ than in controls at 180 days ( $2.94 \pm 0.21$ vs $2.14 \pm 0.17 \mathrm{~kg}$ respectively), but

Table 2 Weight, and linear and volume measurements of pregnant uterus and some conceptus traits for in vivo- and in vitro-produced B. taurus pregnancies carrying females on days 90 and 180 of gestation (LSM \pm S.E.M.).

\begin{tabular}{|c|c|c|c|c|c|c|c|}
\hline \multirow{2}{*}{$\begin{array}{l}\text { Conceptus traits } \\
\text { Females }\end{array}$} & \multicolumn{2}{|c|}{ Day 90} & \multicolumn{2}{|c|}{ Day 180} & \multirow[b]{2}{*}{$\boldsymbol{P}_{\text {group }}$} & \multirow[b]{2}{*}{$P_{\text {day }}$} & \multirow[b]{2}{*}{$\boldsymbol{P}_{\text {group by day }}$} \\
\hline & In vivo & In vitro & In vivo & In vitro & & & \\
\hline Foetal wt, g & $146.0^{\mathrm{a}} \pm 12.9$ & $173.0^{\mathrm{a}} \pm 7.7$ & $6462.4^{b} \pm 171.9$ & $7163.1^{c} \pm 398.7$ & 0.099 & 0.001 & 0.124 \\
\hline Foetal femur, mm & $23.3^{\mathrm{a}} \pm 1.4$ & $24.6^{\mathrm{a}} \pm 0.3$ & $100.3^{\mathrm{b}} \pm 1.5$ & $108.0^{\mathrm{C}} \pm 1.2$ & 0.003 & 0.001 & 0.016 \\
\hline Foetal liver wt, g & $4.6^{a} \pm 0.6$ & $6.6^{a} \pm 0.2$ & $186.8^{b} \pm 7.0$ & $227.0^{C} \pm 20.2$ & 0.059 & 0.001 & 0.081 \\
\hline Foetal heart wt, g & $1.4^{\mathrm{a}} \pm 0.2$ & $1.5^{\mathrm{a}} \pm 0.1$ & $48.5^{b} \pm 1.9$ & $58.5^{\mathrm{c}} \pm 5.0$ & 0.068 & 0.001 & 0.073 \\
\hline Foetal lung wt, g & $4.4^{\mathrm{a}} \pm 0.2$ & $6.9^{\mathrm{a}} \pm 0.2$ & $153.2^{b} \pm 2.7$ & $175.5^{\mathrm{C}} \pm 11.1$ & 0.042 & 0.001 & 0.092 \\
\hline Foetal brain wt, g & $4.6^{\mathrm{a}} \pm 0.4$ & $5.1^{\mathrm{a}} \pm 0.2$ & $83.0^{b} \pm 4.8$ & $74.6^{\mathrm{C}} \pm 0.7$ & 0.112 & 0.001 & 0.072 \\
\hline Foetal kidney wt, g & $1.8^{\mathrm{a}} \pm 0.3$ & $1.6^{\mathrm{a}} \pm 0.2$ & $67.1^{\mathrm{b}} \pm 6.6$ & $102.4^{\mathrm{C}} \pm 11.3$ & 0.017 & 0.001 & 0.016 \\
\hline Genital tract wt, kg & $2.55^{\mathrm{a}} \pm 0.32$ & $2.12^{\mathrm{a}} \pm 0.15$ & $15.48^{\mathrm{b}} \pm 0.93$ & $20.23^{\mathrm{c}} \pm 1.44$ & 0.037 & 0.001 & 0.017 \\
\hline Allantoic fluid vol., I & $0.725^{\mathrm{a}} \pm 0.176$ & $0.429^{a} \pm 0.126$ & $1.303^{\mathrm{a}} \pm 0.671$ & $3.938^{b} \pm 0.705$ & 0.065 & 0.005 & 0.027 \\
\hline Amniotic fluid vol. ${ }^{+}$, I & $0.462^{\mathrm{a}} \pm 0.147$ & $0.532^{\mathrm{a}} \pm 0.028$ & $2.485^{\mathrm{b}} \pm 0.692$ & $1.372^{\mathrm{b}} \pm 0.224$ & 0.158 & 0.002 & 0.115 \\
\hline Placentome wt, g & $123.7^{\mathrm{a}} \pm 37.4$ & $85.0^{\mathrm{a}} \pm 20.3$ & $2213.0^{\mathrm{b}} \pm 28.0$ & $2898.9^{\mathrm{c}} \pm 260.4$ & 0.026 & 0.001 & 0.015 \\
\hline Placentome $\mathrm{SA} *, \mathrm{~cm}^{2}$ & $201.1^{a} \pm 46.6$ & $291.9^{a} \pm 28.7$ & $2459.6^{b} \pm 128.8$ & $3236.1^{\mathrm{b}} \pm 539.7$ & 0.123 & 0.001 & 0.211 \\
\hline
\end{tabular}

\footnotetext{
${ }^{\mathrm{a}, \mathrm{b}, \mathrm{c}}$ Numbers in the same row without common superscripts differ; $P<0.05$.
}

$*$ SA: Surface area, $P=0.0636$ for day- 180 female concepti.

${ }^{\dagger} P=0.0512$ for day-180 female concepti. 
not at 90 days of gestation $(0.93 \pm 0.08$ vs $1.07 \pm 0.13 \mathrm{~kg}$ respectively). Placentomes continued to be longer, wider and thinner in day-180 IVP pregnancies $(P<0.05)$, but the number of placentomes was not different between groups and stage of gestation $(95.9 \pm 11.3$ vs $105.5 \pm 10.4$ placentomes for control and IVP placentas on day 90, and $106.7 \pm 11.3$ vs $102.8 \pm 11.3$ for control and IVP placentas on day 180 respectively), and did not correlate with any other physical trait, irrespective of foetal gender. Uterine (reproductive tract weights, allantoic fluid volume and total fluid volume), placental (placental SA and weight) and foetal (body size and weight, and visceral and muscular weights) physical traits were correlated with one another $(0.760<r<0.999, \quad P<0.05)$. When foetal weight was used as a covariate, differences between days disappeared for many traits (humerus, femur, liver, heart, spleen, supraspinatus and semitendinosus muscles), but not for most of the others. When the females were analysed independently, however, differences between groups $(P<0.05)$ were greater for most uterine, placental and fluid volumes, and foetal traits on day 180 of gestation (Table 2). Moreover, allantoic and amniotic fluid volumes in day-180 IVP concepti were greater $(P<0.05)$ and lesser $(P=0.512)$ than controls respectively (Table 2$)$.

\section{Concentrations of D-glucose, $D$-fructose and L-lactate in the biological fluids}

\section{Days 90 and 180 of gestation (experiment 1)}

On day 90 of gestation, no significant differences were observed for glucose and fructose concentrations in the foetal plasma, and amniotic and allantoic fluids, except for day-90 IVP concepti, which had lower foetal plasma glucose concentrations than controls $(1.66 \pm 0.22$ vs $2.36 \pm 0.24 \mathrm{mM}$ respectively; $P<0.05$ ). On day 180 , following a similar pattern seen for physical traits, higher concentrations of fructose were observed in the foetal plasma of IVP concepti than with controls (8.69 \pm 0.91 vs $6.48 \pm 1.04 \mathrm{mM}$ respectively; $P<0.05)$. Concentrations of fructose in the maternal plasma in both groups on days 90 and 180 were negligible and not different from zero in all females $(\leq 0.10 \mathrm{mM})$. From early to late pregnancy (days 90 to 180), regardless of experimental group, significant decreases in the concentrations of glucose were observed in the foetal plasma and associated fluids $(P<0.05)$, whereas concentrations of fructose in the amniotic fluid, and total glucose and fructose accumulated in each fluid, and in both combined, increased during the same period $(P<0.05)$. Maternal plasma lactate concentrations were lower in the IVP group on day 90 (5.30 \pm 0.73 vs $8.20 \pm 0.81 \mathrm{mM}$ for IVP and controls respectively; $P<0.05$ ), but not on day 180 of gestation. No differences in foetal lactate concentrations were seen between groups. However, lactate concentrations were higher in foetal plasma (9.77 \pm 0.72 vs $6.74 \pm 0.82 \mathrm{mM} ; P<0.05)$ and lower in allantoic fluid $(0.64 \pm 0.19$ vs $2.76 \pm 0.20 \mathrm{mM}$;
$P<0.05$ ) on day 180 than on day 90 respectively, irrespective of the experimental group.

The analysis of glucose, fructose and lactate in the plasma (maternal or foetal) and foetal fluids (amniotic or allantoic) was also carried out separately for female foetuses. On day 90 of pregnancy, maternal and foetal glucose levels (Fig. 1a), and maternal and allantoic lactate concentrations (Fig. 1C) in IVP female concepti were significantly lower than controls $(P<0.05)$. On day 180, fructose concentrations in IVP female concepti were higher $(P<0.05)$ in foetal plasma and amniotic and allantoic fluids (Fig. $1 b$ ). Lactate concentrations in the amniotic fluid (Fig. 1C), and the total accumulated amounts of glucose and fructose in the allantoic fluid and in total foetal fluids were also significantly higher $(P<0.05)$ in day-180 IVP female concepti than controls (Fig. $1 c$ and $d$ ). From days 90 to 180 of pregnancy, total fructose increased by 10 -fold in the amniotic fluid $(P<0.05)$ and in both fluids combined $(P<0.05)$, irrespective of the groups (Fig. $1 d$ ). Group differences were also apparent, as total glucose and fructose were greater in the allantoic fluid of day-180 than day-90 pregnancies only in the IVP group $(P<0.05)$. Amounts of glucose observed in combined foetal fluids (total fluids) also demonstrated a threefold significant temporal increase only in the IVP group $(P<0.05)$. No temporal differences were observed in the concentrations of fructose in the foetal plasma for the control group, but these values were higher $(P<0.05)$ in day-180 than day-90 IVP concepti. Glucose concentrations in the foetal plasma (control group) and foetal fluids (both groups) declined $(P<0.05)$ from days 90 to 180 of gestation (Fig. 1a), whereas fructose concentrations (Fig. $1 b$ ), for the same time period, increased in the foetal fluid and amniotic fluid in the IVP group $(P<0.05)$, and were negatively correlated with glucose concentrations in the fluids $(-0.669<r<-0.810 ; \quad P<0.05)$. Maternal plasma glucose concentrations were positively correlated with glucose concentrations in foetal plasma, and total glucose and fructose in the allantoic fluid and total foetal fluids $(0.624<r<0.878 ; P<0.05)$. Foetal plasma and amniotic and allantoic fluid glucose concentrations positively correlated with one another $(0.700<r<0.915$; $P<0.05)$ but negatively correlated with most conceptus component weights $(-0.638<r<-0.908 ; P<0.05)$. By contrast, concentrations of fructose in the amniotic fluid, and total sugars (glucose and fructose) in each foetal fluid and in total foetal fluids, were positively correlated with conceptus component weights (0.610<r<0.929; $P<0.05)$.

\section{Neonatal plasma substrate concentrations (experiment 2)}

In vitro-derived calves displayed significantly higher concentrations of plasma fructose than controls at 10 and 60 min after birth $(P<0.05)$; these subsequently became similar, whereas no differences in plasma glucose and lactate concentrations were detected between groups in the first $24 \mathrm{~h}$ (Fig. 2). Significant differences were observed 
(a) D-glucose

In vivo Day $90 \quad \square$ In vitro Day $90 \quad \square$ In vivo Day $180 \quad \square$ In vitro Day 180

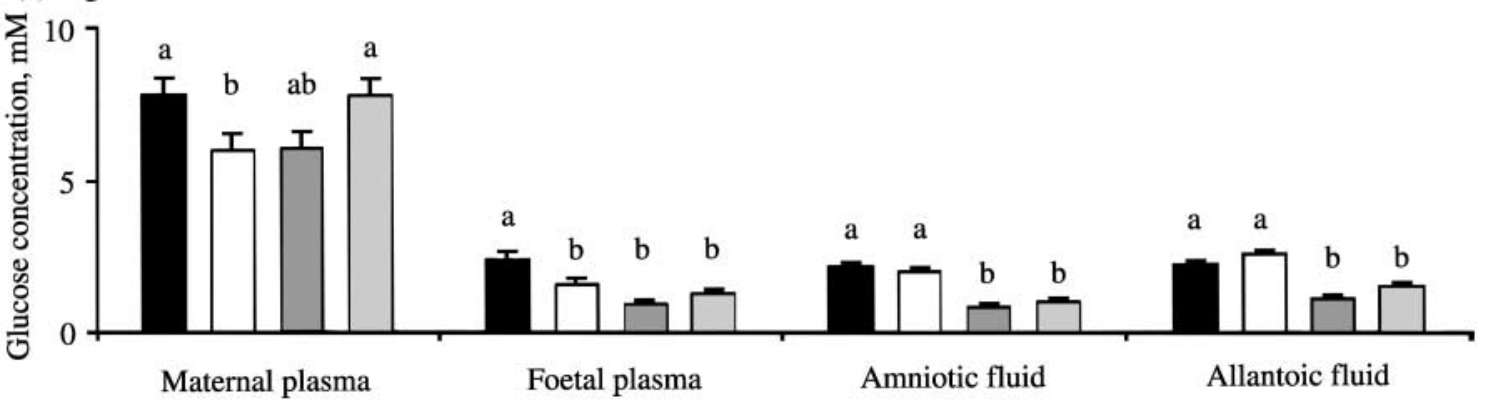

(b) D-fructose

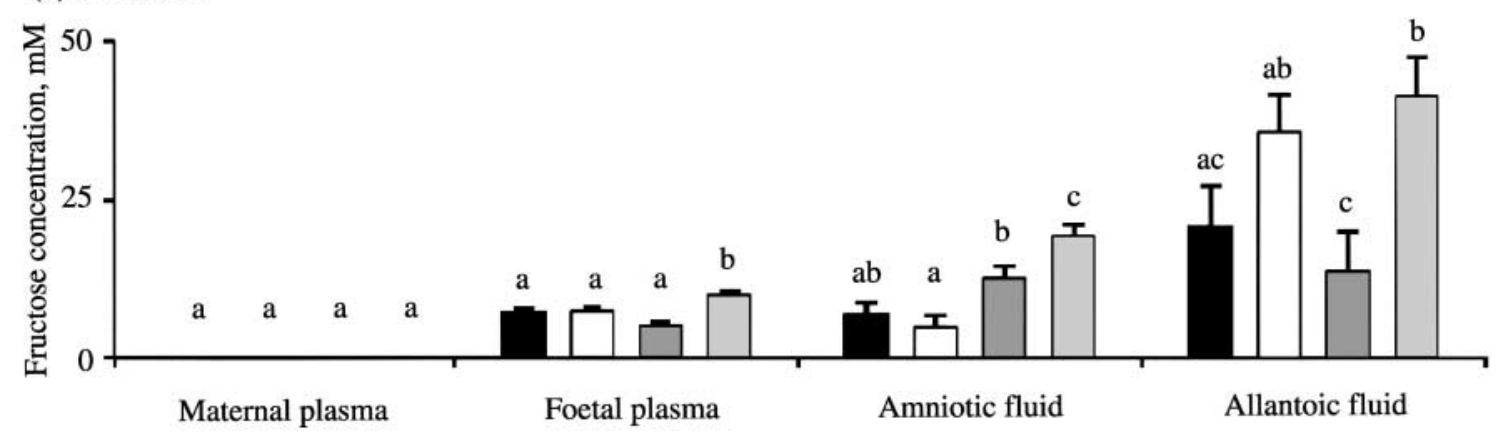

(c) L-lactate

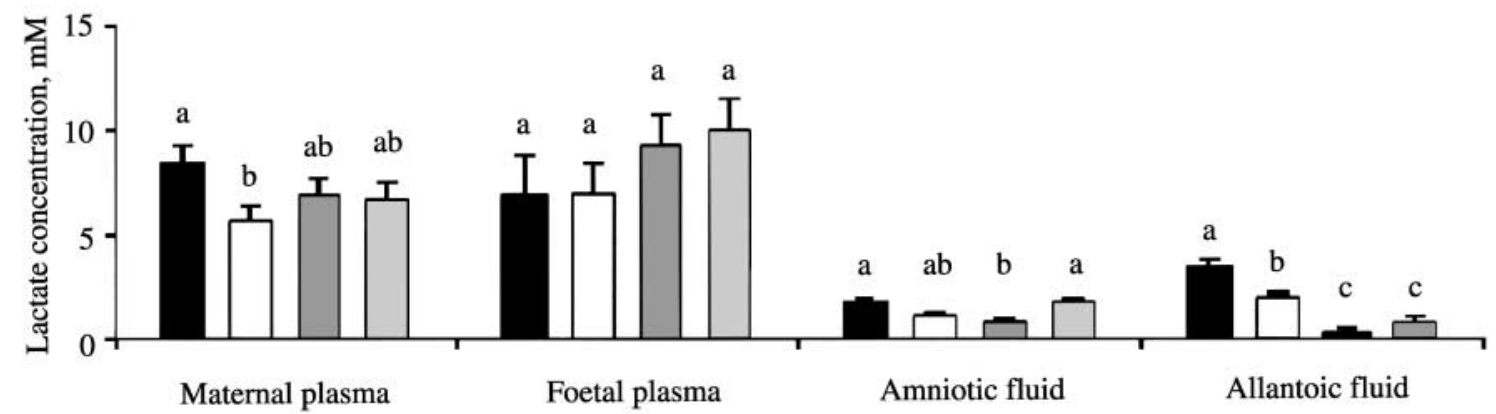

(d) Total D-glucose and Total D-fructose in foetal fluids

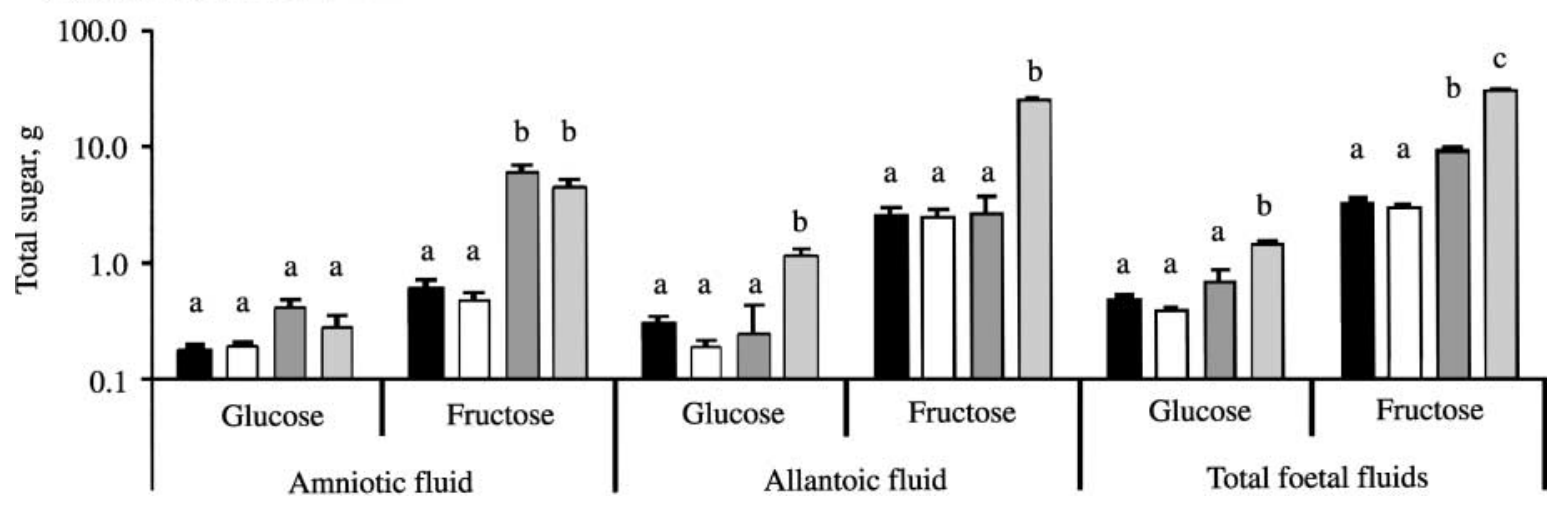

Figure 1 Substrate concentrations ( $\mathrm{mM}$ ) and total amounts $(\mathrm{g})$ in the plasma and foetal fluids in in vivo- and in vitro-derived B. taurus pregnancies carrying female concepti on days 90 and 180 of gestation (LSM \pm S.E.M.). (a) D-Glucose concentrations; (b) D-fructose concentrations; (c) L-lactate concentrations; (d) total D-glucose and D-fructose, logarithmic scale. Columns in the same group of fluid type and sugar without common superscripts $\left({ }^{\mathrm{a}-\mathrm{d}}\right)$ differ; $P<0.05$. 

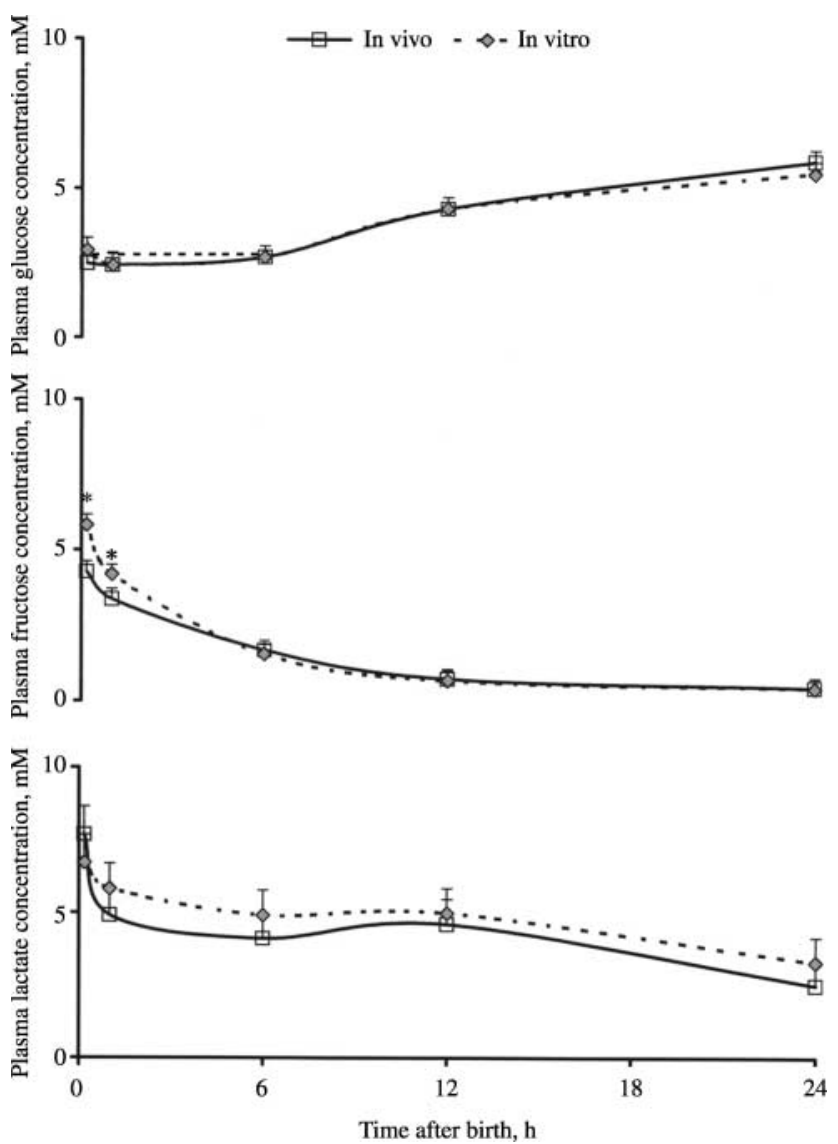

Figure $2 \mathrm{D}$-Glucose, D-fructose and L-lactate concentrations $(\mathrm{mM})$ in the plasma of in vivo- and in vitro-derived $B$. taurus newborn calves at $10 \mathrm{~min}$, and 1, 6, 12 and $24 \mathrm{~h}$ after birth (LSM \pm S.E.M.). $* P<0.05$.

between time points, from $10 \mathrm{~min}$ to $24 \mathrm{~h}(P<0.05)$, for all three substrates in both experimental groups. In general, plasma glucose concentrations slightly fell within the first hour after birth, to increase steadily and gradually to values above $5 \mathrm{mM}$ at $24 \mathrm{~h}$ after delivery in both groups. Conversely, concentrations of fructose in the neonatal plasma were initially high $(4.2$ and $5.8 \mathrm{mM}$ for in vivo- and in vitro-derived calves respectively) but decreased within the first $6-12 \mathrm{~h}$ after birth, reaching steady but low values afterwards $(<0.5 \mathrm{mM}$ for both groups). Lactate concentrations were significantly $(P<0.05)$ higher at $10 \mathrm{~min}$ $(>7 \mathrm{mM})$ and lower at $24 \mathrm{~h}(<3 \mathrm{mM})$ compared with the intermediate values $(4.5-5.4 \mathrm{mM})$ observed at the other time points (1, 6 and $12 \mathrm{~h}$ ). The combined total amount of glucose and fructose was significantly higher in IVP calves at $10 \mathrm{~min}$, becoming similar afterwards $(P<0.05)$. A negative correlation was observed between glucose and fructose concentrations as a function of time $(r=-0.710, P<0.05)$.

\section{Blood and fluid chemistry during and after pregnancy}

\section{Days 90 and 180 of gestation (experiment 1)}

No differences were observed between groups regarding the concentrations of $\mathrm{Na}^{+}, \mathrm{K}^{+}$and $\mathrm{Cl}^{-}$, total protein and creatinine for each gestation period (days 90 or 180), and foetal fluid (Fig. 3a-e), irrespective of foetal gender. Osmolarity was significantly higher $(P<0.05)$ in the amniotic fluid of day-180 IVP concepti (Fig. 3f). Plasma fructose concentration positively correlated with plasma osmolarity in the foetus $(r=0.821, P<0.05)$, and foetal plasma glucose concentrations and total glucose and fructose in the foetal fluids were positively correlated with the osmolarity in each fluid type $(r>0.628, P<0.05)$.

\section{Newborn calves (experiment 2)}

No differences were seen in heart rate, $\mathrm{HCO}_{3}^{-}$and $\mathrm{Ca}^{2+}$ (data not shown) concentrations, PCV and TPP between groups at any given time point (Fig. 4). Some values for blood $\mathrm{pCO}_{2}, \mathrm{pO}_{2}$ and $\mathrm{Na}^{+}$were elevated in IVP calves at $6 \mathrm{~h}\left(\mathrm{Na}^{+} ; P<0.05\right), 12 \mathrm{~h}\left(\mathrm{Na}^{+} ; P<0.05\right)$ and $24 \mathrm{~h}\left(\mathrm{Na}^{+}\right.$ and $\left.\mathrm{pO}_{2} ; P<0.05\right)$, or reduced at $12 \mathrm{~h}\left(\mathrm{pCO}_{2} ; P<0.05\right)$ after birth (Fig. 4). Animals within each group were highly variable for rectal temperature, respiratory rate and $\mathrm{pCO}_{2}$, and appeared to show attenuated differences between groups for those observed variables. Significant differences were observed between time points $(P<0.05)$ for rectal temperature, respiratory rate and blood $\mathrm{pH}$. Blood $\mathrm{pH}$ and respiratory rate were positively correlated with one 

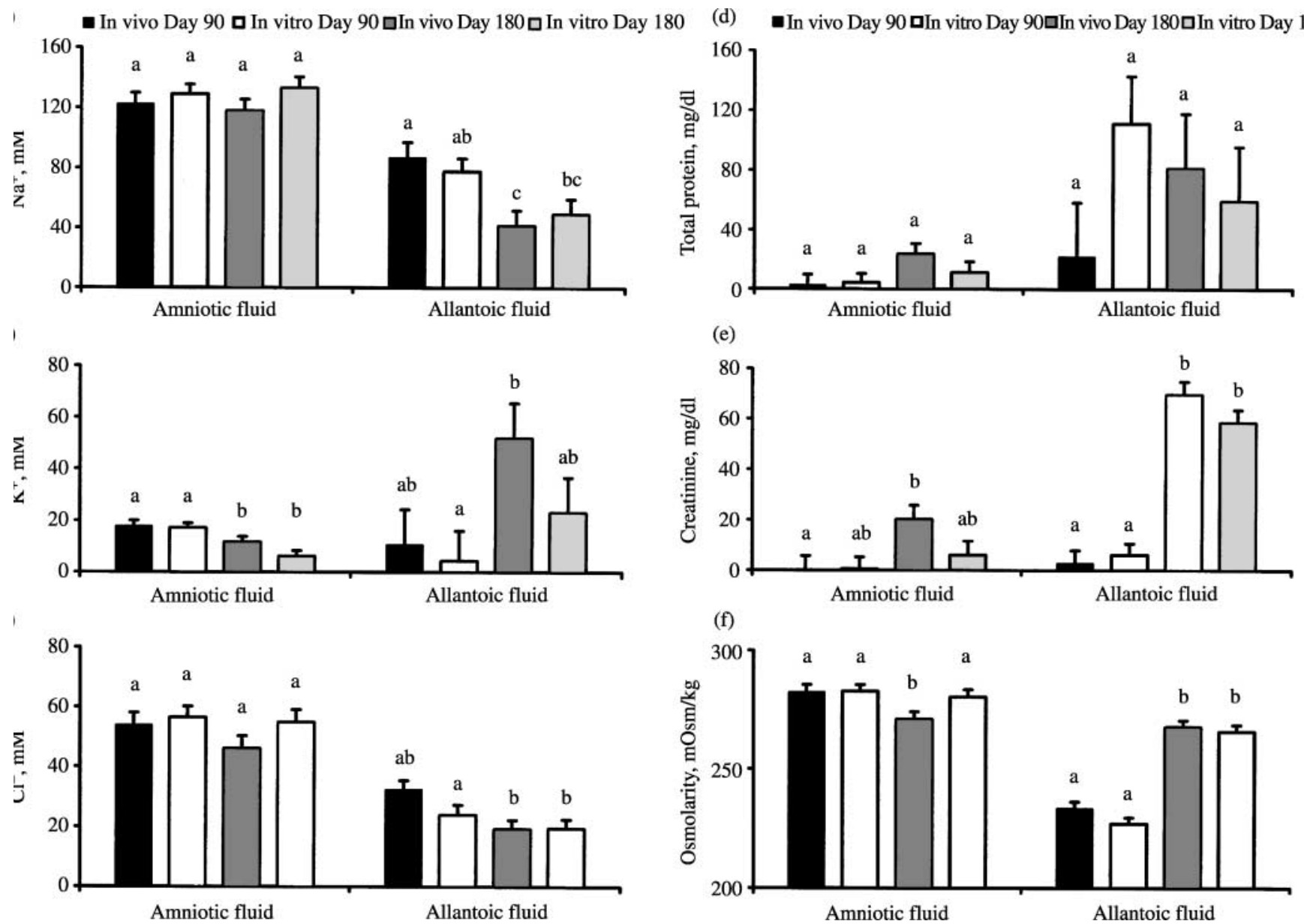

Figure 3 Physicochemical characteristics of foetal fluids in in vivo- and in vitro-derived B. taurus pregnancies carrying female concepti on days 90 and 180 of gestation (LSM \pm S.E.M.). (a) $\left[\mathrm{Na}^{+}\right]$, in $\mathrm{mM}$; (b) $\left[\mathrm{K}^{+}\right]$, in $\mathrm{mM}$; (c) $\left[\mathrm{Cl}^{-}\right]$, in $\mathrm{mM}$; (d) total protein, in $\mathrm{mg} / \mathrm{dl}$; (e) creatinine concentrations, in $\mathrm{mg} / \mathrm{dl}$; (f) osmolarity, in $\mathrm{mOsm} / \mathrm{kg}$. Columns without common superscripts ${ }^{\mathrm{a}, \mathrm{b}}$ ) differ; $P<0.05$.

another $(r=0.931, P<0.05)$ and with plasma glucose concentrations $(r=0.738, P<0.05)$, and negatively correlated with blood $\mathrm{pCO}_{2}(r>-0.946, P<0.05)$ and plasma fructose and lactate concentrations $(r>-0.865$, $P<0.05)$, which in turn were mutually correlated $(r=0.965, P<0.05)$.

\section{Relative transcription in placental tissue}

No differences were detected in the relative transcription of the glucose transporters Glut-1, -3 and -5 in placentomes (data not shown) between groups (IVP and control) and gestation period (days 90 and 180). Levels of expression were similar between Glut-1 and -3 genes, irrespective of group or gestation period. However, levels of expression of Glut-5 were 10-100-fold higher than the other two genes, with higher variation among samples. Nevertheless, relative transcription of Glut-5 was correlated with allantoic and total foetal fluid volumes, and with total glucose and fructose accumulated in the allantoic fluid and total foetal fluids $(r>0.600, P<0.05)$.

\section{Discussion}

The IVP system utilized in this study has been implicated in the appearance of symptoms characteristic of the large calf syndrome (Behboodi et al. 1995, Bertolini \& Anderson 2002, Bertolini et al. 2002 b). As in this study, we have observed that in vivo and IVP concepti and neonates display distinct morphological, functional and molecular features at several different time points during pregnancy. Abnormalities in IVP concepti were found to be associated with consistent placental abnormalities manifested since early stages of gestation (Bertolini et al. 2001, 2002a,b, 2003, 2004, Bertolini \& Anderson 2002). Giant placentomes and cotyledons were consistently present in IVP pregnancies and at term (Bertolini et al. $2002 b$ ). In this study, no major significant distinctions were observed between IVP and controls on day 90 of gestation, except for placentome measurements, which were larger in IVP pregnancies. On day 180 of gestation, IVP pregnancies displayed larger uteri and concepti, and at term, calves were delivered heavier than controls, with consistent foetal membrane (FM) abnormalities (Bertolini 
(a)

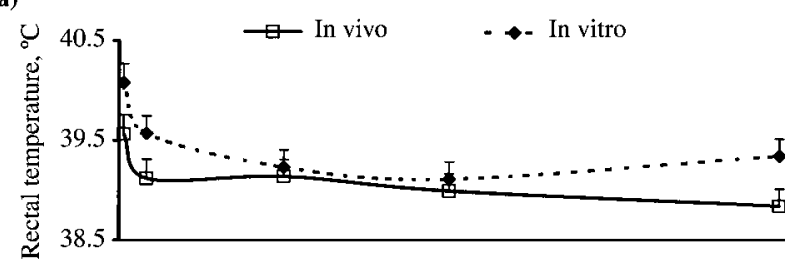

(b)

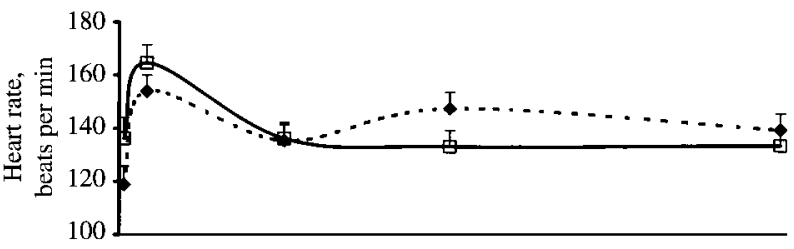

(c)

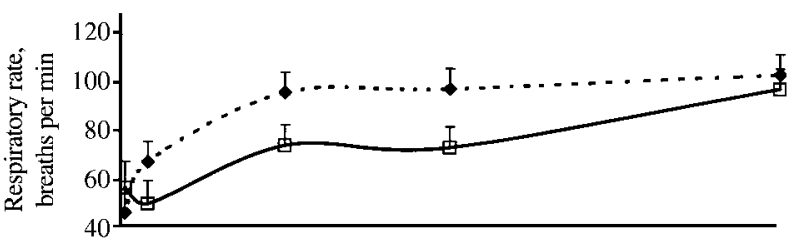

(d)

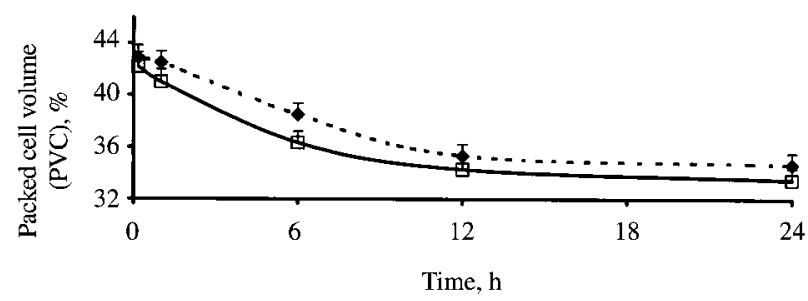

(e)

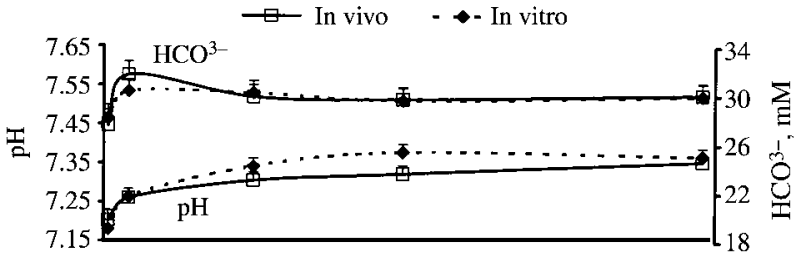

(f)

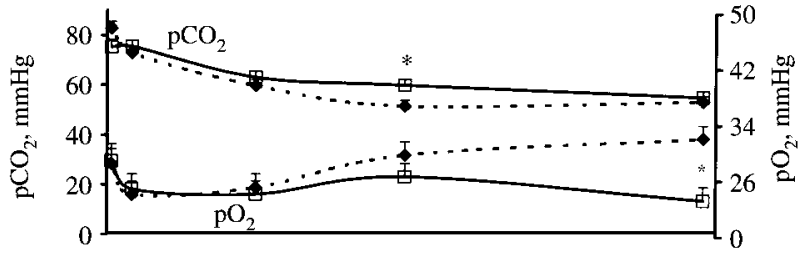

(g)

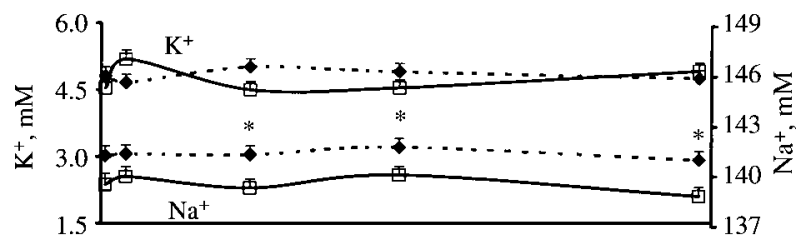

(h)

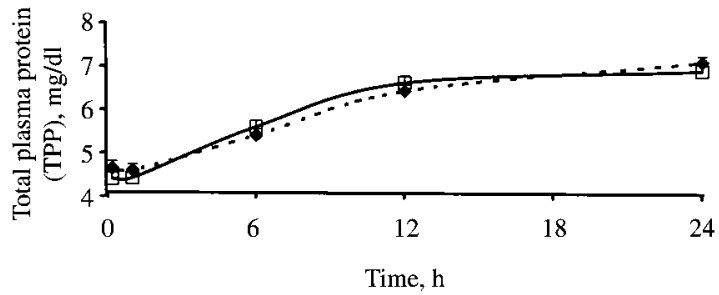

Figure 4 Clinical and physiological characteristics of in vivo- and in vitro-derived $B$. taurus newborn calves at $10 \mathrm{~min}$, and 1, 6, 12 and $24 \mathrm{~h}$ after birth (LSM \pm S.E.M.). (a) Rectal temperature $\left({ }^{\circ} \mathrm{C}\right) ;(b)$ heart rate, in beats/min; $(c)$ respiratory rate, in breath/min; $(d)$ packed cell volume $(\mathrm{PCV})$ $(\%) ;(e) \mathrm{pH}$ and $\left[\mathrm{HCO}_{3}^{-}\right]$, in $\mathrm{mM} ;(f) \mathrm{pCO}_{2}$ and $\mathrm{pO}_{2}$, in $\mathrm{mmHg}$; $(g)\left[\mathrm{Na}^{+}\right]$and $\left[\mathrm{K}^{+}\right]$, in $\mathrm{mM} ;(h)$ total plasma protein (TPP), in $\mathrm{mg} / \mathrm{dl} . * P<0.05$.

\& Anderson 2002, Bertolini et al. 2002b), such as changes in placentome size. A reduction in the number of placentomes and the appearance of large placentomes and cotyledons larger than $15 \mathrm{~cm}$ in diameter in the FM appear to be a compensatory mechanism for inadequate foetomaternal attachment (Roberts 1986, Cibelli et al. 1998, Hill et al. 1999, 2000, Bertolini et al. 2002b), in a manner similar to that reported for sheep after surgical removal of caruncles (Alexander 1964). This corroborates our observation that placentomes immediately surrounding the foetus, in the mid-region of the foetal horn, were initially smaller than controls but became longer and thinner from mid- to late first trimester of IVP pregnancies (Bertolini et al. 2002b). Placentome size distribution differed between groups on days 90 and 180 of gestation, with the presence of enlarged placentomes and cotyledons on the FM of IVP concepti being associated with a larger gross SA in the foetal horn on day 180 and at term.
The high pregnancy losses in this study, precisely during the time of placental formation, suggest that embryonic death may be a consequence of faulty placentation, possibly due to a delay in chorioallantoic development, as proposed for bovine clone pregnancies by Hill et al. (2000) and Hashizume et al. (2002). As a consequence, an insufficient inflow and outflow of nutrients and metabolites may fail to support the high metabolic demand imposed by organogenesis and membrane development.

Our findings indicate that in vitro-derived pregnancies not only sustain larger concepti toward the end of the second trimester of pregnancy, but also demonstrate a two- to fourfold increase in the accumulation of fructose by the conceptus into the foetal circulation and associated fluids in mid- to late pregnancy, and such differences could still be detected in the neonatal plasma soon after birth. A higher glucose uptake by IVP placentas, perhaps due to differences in placental mass and SA seen in 
day-180 IVP concepti and term FM (Bertolini et al. $2002 b$ ), could both promote an increase in synthesis and disposition of fructose into the foetal plasma and fluids, and boost foetal growth in IVP pregnancies. Fructose is the primary reducing sugar in foetal plasma and fluids, and such high concentrations appear to be a peculiarity of Ungulata and Cetacea (Goodwin 1956, Nixon 1963). These species bear similar placental types (synepithelioor epitheliochorial placentas) and maintain relatively low maternal glucose concentrations, which may require placental fructogenic capacity to supply the concepti with adequate amounts of reducing sugars during pregnancy (Goodwin 1956, Hugget \& Nixon 1961). An increase in glucose supply and consumption by the placenta linearly redirects the use of this substrate to non-oxidative pathways, such as fructose synthesis (Meznarich et al. 1987, Hay 1995). Placental fructose production may be a byproduct of the foetal need on occasion to supply glucose to the placenta, preventing glucose loss to the mother, as fructose does not cross the foetomaternal barrier, and limiting foetal glucose uptake when placental needs are high (Gu et al. 1987). Fructose and lactate, another by-product of glucose metabolism by the placental tissue, are of significance to the total conceptus and placental oxidative metabolism (McGowan et al. 1995). Aldoretta and Hay (1999) demonstrated in sheep that the rate at which the placental tissue synthesizes fructose seems to depend directly on the placental glucose supply. As placental mass and SA become significantly larger in IVP concepti, more placental glucose utilization or transport may occur in IVP concepti.

An increase in placental glucose consumption plays an active role in foetal physiological hypoglycaemia (Simmons et al. 1979, Hay 1995), with the uteroplacental tissue consuming $60 \%$ or more of this substrate for its own metabolic functions (Bell et al. 1999). This contributes to the glucose concentration gradient, promoting an increase in foetoplacental uptake (Simmons et al. 1979, Hay 1995). Some results have demonstrated that foetal glucose uptake varies between $11 \%$ and $17 \%$ of total uterine uptake around day 180 of gestation (Reynolds et al. 1986, Ferrell 1991b). However, in the present study, concentrations of glucose in foetal plasma were similar between groups and were $20-30 \%$ of maternal levels, a finding consistent with previous reports in cattle (Reynolds et al. 1990), but more glucose was converted into fructose by the placenta, resulting in accumulation in foetal plasma and fluids. In addition, our findings suggest that more glucose was made available to the foetus to support the accelerated growth pattern in IVP concepti, since enhanced substrate availability to IVP foetuses would be required to support greater foetal growth during late pregnancy and delivery of larger and heavier IVP calves. No differences in the relative abundance of transcripts for important components of the glucose transport system (Glut-1, -3 and -5) were detected at the placental level (Bertolini et al. 2003, for Glut-1 and -3). Consequently, the increase in total glucose and fructose accumulation, and decreased glucose concentrations in the foetal plasma and fluids, were associated with larger uterine, placental and foetal weights, and an increase in placental SA, reflecting a likely increase in substrate utilization by fastgrowing IVP concepti.

As most of the nutrients transferred across the placenta are metabolized and/or produced by the placenta (Ferrell et al. 1983, Ferrell 1989), deregulations in placental function and metabolism may cause changes in the placenta's constraining effect on foetal growth after in vitro embryo manipulations. Interestingly, maternal nutrient restriction during early to mid-pregnancy in cattle (Perry et al. 1999), sheep and humans (reviewed by Symonds et al. 2001), followed by an increase in or a restoration of nutrient levels, appears to cause a similar pattern of changes in placental development and/or foetal growth, as seen in this study. Under physiological conditions, foetal growth occurs slowly during early pregnancy and accelerates exponentially during later stages (Eley et al. 1978, Prior \& Laster 1979, Ferrell 1989, Reynolds et al. 1990). However, the placenta grows faster than the foetus in early pregnancy, placental weight being greater than foetal weight during the first trimester of gestation. Placental growth slows after midgestation, and foetal weight surpasses that of the placenta (Eley et al. 1978, Prior \& Laster 1979, Ferrell 1989, Reynolds et al. 1990). This initial period of faster growth of the placenta is thought to be important to allow the foetus to grow exponentially during the second and third trimesters of gestation (Eley et al. 1978, Prior \& Laster 1979, Ferrell 1989, Reynolds et al. 1990). The absolute foetal and placental growth continues to increase until delivery, but the decline in the relative foetal growth in the last weeks of gestation is believed to be a consequence of restraint imposed on the foetus by the placenta towards the end of gestation, when foetal demands for nutrients are at their greatest (Prior \& Laster 1979, Reynolds et al. 1990). The low nutrient intake restricts placental development, which coincides with the period of fast placental growth. As a result of restoring dietary values in mid- to late pregnancy, newborns are usually longer and heavier, and placentas are larger (Perry et al. 1999, Symonds et al. 2001). We observed a similar biphasic growth pattern in IVP pregnancies characterized by conceptus growth retardation on day 16 and in early pregnancy, and followed by changes in the development of placental tissue, culminating in the delivery of calves that were $33 \%$ larger at term than controls (Bertolini et al. 2002a,b). The mechanisms behind this phenomenon are still unclear, but are likely to be due to functional and structural changes in the placental tissue as a response to accommodate the initial period of growth restriction.

An increased incidence of hydroallantois has been described in in vitro-derived pregnancies in cattle (Hasler et al. 1995, Walker et al. 1996, Cibelli et al. 1998, Van Wagtedonk-de Leew et al. 1998, 2000), but its causes and 
progression during pregnancy are still unclear. No clinical or biochemical cases of hydrops of the foetal membranes were diagnosed in our studies, but fluid volumes differed on day 180 of gestation, being higher in the amniotic and allantoic compartments in control and IVP pregnancies respectively. Under physiological conditions, generally direct or inverse relationships occur between the composition of the amniotic or allantoic fluids respectively, and the extracellular fluid electrolyte compositions (Skydsgaard 1965, Wintour et al. 1986). Pathological variations in cases of hydrops of the foetal membranes are usually associated with dramatic changes in fluid composition (Wintour et al. 1986). In this study, there were no distinctions in fluid composition (electrolytes, total protein and creatinine) between groups that could relate to differences in fluid volumes, or indicate a pathological condition. However, more sugar moieties were observed in the amniotic fluid of control animals, or in the allantoic fluid of IVP pregnancies, which coincided with the differences in fluid volume on day 180, suggesting an increase in total glucose transferred across the placenta in IVP pregnancies. Perhaps, due to the osmotically active nature of glucose and fructose, an increase or decrease in sugar moieties in those fluids in IVP pregnancies could have exerted an osmotic effect on fluid accumulation and total volume, as can be inferred by the existence of positive correlations between volume, osmolarity and sugar concentrations in the fluids.

In plasma of newborn calves from both groups, there were close associations of the blood gases and acid-base balance status, coupled with compensatory mechanisms, with the plasma profiles of the substrates measured in this study. Neonatal hypoxia, mainly caused by respiratory distress, may also lead to lactate acidosis, which causes subsequent changes in the acid-base balance and blood chemistry homeostasis (Torrance \& Wittnich 1994, Sacks 1999). Hyperfructosaemia may contribute to lactate production, as the metabolism of fructose bypasses key metabolic regulatory steps, potentially causing disturbances in the acid-base balance, but fructose can also be rerouted to the synthesis of glucose and glycogen, as seen during hypoglycaemic conditions such as starvation (Mayes 1993). Plasma from IVP calves had significantly higher concentrations of fructose in the first $60 \mathrm{~min}$ after birth, but excessive plasma fructose was quickly cleared, while glycaemia started to rise and stabilize after $6 \mathrm{~h}$ postpartum. The negative correlation between fructose and glucose concentrations in the neonatal plasma suggests that fructose usage may have participated in the increase in glycaemia. On the other hand, lactate and fructose concentrations paralleled one another, and by association both appeared to have affected the acid-base balance and respiratory rate, more evidently in IVP calves. According to blood $\mathrm{pH}$ (Fig. 4e) and plasma lactate concentrations (Fig. 2), newborn calves in both groups manifested clinical lactate acidosis during the first hour after birth, since, in humans, lactate concentrations above
$5 \mathrm{mM}$ and $\mathrm{pH}$ below 7.25 are indicative of severe lactic acidosis (Sacks 1999). Despite the normalization of blood $\mathrm{pH}$ after the first hour, lactate levels remained above $5 \mathrm{mM}$ for several hours in IVP calves, whereas lactate levels dropped below $5 \mathrm{mM}$ within the first hour postpartum in control calves. Since hyperfructosaemia may cause lactic acidosis (Van den Berghe 1994), it is possible that, once ventilation normalized and fructose levels decreased, lactate production diminished, allowing the acid-base balance to return to normal. It is known that, in cases of metabolic acidosis (as in lactate accumulation), respiratory compensation is usually delayed for a few hours until the cerebrospinal fluid, and cerebral interstitial and plasma bicarbonate equilibrate (Seri 1998). Following the initial period of metabolic acidosis, newborn calves underwent a period of compensatory respiratory alkalosis, with a slight increase in blood $\mathrm{pH}$ and a decrease in $\mathrm{pCO}_{2}$, due to increased respiratory rate, with no differences in bicarbonate concentrations. Increases in respiratory rate and $\mathrm{pO}_{2}$ were attained faster in the IVP group. It is possible that the presence of pregnancy-derived high fructose levels in the plasma of newborn calves may be metabolically and clinically beneficial for postnatal adaptation of life ex utero, under normoxic conditions. However, deviations from physiological normality (as in respiratory distress) may cause metabolic consequences that compromise peri- and postnatal survival.

Values for blood chemistry in animals examined in this study were somewhat similar to those reported by Jacobsen et al. (2000) and Sangild et al. (2000) for IVP calves, and by Garry et al. (1996) and Chavatte-Palmer et al. (2002) for clone calves. From this and the results of the aforementioned studies, deviations in blood chemistry appeared to be influenced by calving ease and birth weight. As many IVP and clone calves are born larger, a trend exists for changes in several clinical and hematological characteristics in the neonate. Nevertheless, most blood parameters appeared to have stabilized by $6 \mathrm{~h}$ after birth, as also described by Jacobsen et al. (2000).

In summary, we have performed a systematic comparison of placentas from in vitro- and in vivo-derived bovine embryos at distinct stages of development to determine whether developmental and physiological abnormalities could be detected during the course of pregnancy, and correlations or associations between such prenatal aberrations and postpartum characteristics of the newborn and FM could be obtained. Morphological and physiological evidence obtained in this study supports the concept that an increase in glucose supply to the placental tissue occurs in IVP pregnancies, enhancing foetal growth toward the end of gestation. The higher concentrations of fructose in day-180 IVP concepti also indicate that more glucose was converted to fructose by the placental tissue. Such differences in placental transfer capacity may be caused by a loss of placental constraint on foetal growth induced by early conceptus growth retardation, but its real nature still needs to be investigated. Further studies are required to 
determine the mechanisms, kinetics and fate of the placental substrate transport and differential fructose synthesis, and to evaluate the effect of pregnancy-derived higher fructose levels in the plasma of newborn calves on peri- and postnatal survival and adaptation to life ex utero. Causeand-effect relationships between substrate supply to the bovine foetus and accelerated prenatal growth after in vitro embryo manipulation also need to be clarified.

\section{Acknowledgements}

The authors thank M.L. Sween and D.J. Kominek for their excellent technical assistance, and interns, students and staff at the Beef Cattle Facilities of the Department of Animal Science and the Sierra Foothill Research and Extension Center of the University of California, for their assistance and for care of the animals. The blood and fluid chemistry analyses and the real-time TaqMan PCR procedures were performed at the Biochemistry Laboratory and at the Lucy Whittier Molecular Core Facility, respectively, at the School of Veterinary Medicine, University of California, Davis.

\section{References}

Aldoretta P \& Hay WW 1999 Effect of glucose supply on ovine uteroplacental glucose metabolism. American Journal of Physiology 277 R947-R958.

Alexander G 1964 Studies on the placenta of the sheep (Ovis aries L.): effect of surgical reduction in the number of caruncles. Journal of Reproduction and Fertility 7 307-322.

Behboodi E, Anderson GB, BonDurant RH, Cargill SL, Kreuscher BR, Medrano JF \& Murray JD 1995 Birth of large calves that developed from in vitro-derived bovine embryos. Theriogenology $\mathbf{4 4}$ 227-232.

Bell AW, Hay WW \& Ehrhardt RA 1999 Placental transport of nutrients and its implications for fetal growth. Journal of Reproduction and Fertility Supplement 54 401-410.

Bertolini M \& Anderson GB 2002 The placenta as a contributor to production of large calves. Theriogenology 57 181-187.

Bertolini M, Mason JB, Sainz RD, Roberts AJ \& Anderson GB 2001 Association of IGF-1 and IGF-2 with fetal development at days 90 and 180 of gestation for in vivo- and in vitro-derived bovine pregnancies. Theriogenology 55347.

Bertolini M, Beam SW, Shim H, Bertolini LR, Moyer AL, Famula TR \& Anderson GB 2002a Growth, development and gene expression by in vivo- and in vitro-produced day-7 and day-16 bovine embryos. Molecular Reproduction and Development 63 318-328.

Bertolini M, Mason JB, Beam SW, Carneiro GF, Sween ML, Moyer AL, Famula TR, Sainz RD \& Anderson GB 2002b Morphology and morphometry of in vivo- and in vitro-produced bovine concepti from early pregnancy to term and association with high birth weights. Theriogenology 58 973-994.

Bertolini M, Mason JB, Batchelder CA, Hoffert KA \& Anderson GB 2003 Relative pattern of gene expression in placental and fetal tissues by in vivo- and in vitro-produced day-90 and day-180 bovine concepti. Theriogenology 59429.

Bertolini M, Wallace CR \& Anderson GB 2004 Bovine placental lactogen (bPL) and bovine pregnancy-specific protein B (bPSPB) as indirect measures of placental function in in vitro-derived bovine pregnancies. Reproduction, Fertility, and Development 16204.

Chavatte-Palmer R, Heyman Y, Richard C, Monget P, LeBourhis D, Kann G, Chilliard Y, Vignon X \& Renard JP 2002 Clinical, hormonal, and hematologic characteristics of bovine calves derived from nuclei from somatic cells. Biology of Reproduction $\mathbf{6 6}$ 1596-1603.

Cibelli JB, Stice SL, Golueke PJ, Kane JJ, Jerry J, Blackwell C, de León FAP \& Robl JM 1998 Cloned transgenic calves produced from nonquiescent fetal fibroblasts. Science 280 1256-1258.

Ehrhardt RA \& Bell AW 1997 Developmental increase in glucose transporter concentration in the sheep placenta. American Journal of Physiology 273 R1132-R1141.

Eley RM, Thatcher WW, Bazer FW, Wilcox CJ, Becker RB, Head HH \& Adkinson RW 1978 Development of the conceptus in the bovine. Journal of Dairy Science 61 467-473.

Farin PW \& Farin CE 1995 Transfer of bovine embryos produced in vivo or in vitro: survival and fetal development. Biology of Reproduction 52 676-682.

Farin PW, Crosier AE \& Farin CE 2001 Influence of in vitro systems on embryo survival and fetal development in cattle. Theriogenology 55 151-170.

Ferrell CL 1989 Placental regulation of fetal growth. In Animal Growth Regulation, pp 1-19. Eds DR Campion, GJ Hausman \& RJ Martin. New York: Plenum Press.

Ferrell CL 1991a Maternal and fetal influences on uterine and conceptus development in the cow. I. Growth of the tissues of the gravid uterus. Journal of Animal Science 69 1945-1953.

Ferrell CL 1991b Maternal and fetal influences on uterine and conceptus development in the cow. II. Blood flow and nutrient flux. Journal of Animal Science 69 1954-1965.

Ferrell CL \& Reynolds LP 1992 Uterine and umbilical blood flows and net nutrient uptake by fetuses and uteroplacental tissues of cows gravid with either single or twin fetuses. Journal of Animal Science 70 426-433.

Ferrell CL, Ford SP, Prior RL \& Christenson RK 1983 Blood flow, steroid secretion and nutrient uptake of the gravid bovine uterus and fetus. Journal of Animal Science 56 656-667.

Froesch ER 1976 Disorders of fructose metabolism. Clinical Endocrinology and Metabolism 5 599-611.

Garry FB, Adams R, McCann JP \& Odde KG 1996 Postnatal characteristics of calves produced by nuclear transfer cloning. Theriogenology 45 141-152.

Girniene J, Tatibouet A, Sacckus A, Yang J, Holman GD \& Rollin P 2003 Inhibition of the D-fructose transporter protein GLUT5 by fused-ring glyco-1,3-oxazolididn-2-thiones and -oxazolindin-2ones. Carbohydrate Research 338 711-719.

Gluckman PD, Morel PCH, Ambler GR, Breier BH, Blair HT \& McCutcheon SN 1992 Elevating maternal insulin-like growth factor-I in mice and rats alters the pattern of fetal growth by removing maternal constraint. Journal of Endocrinology 134 R1-R3.

Goodwin RFW 1956 Division of the common mammals into two groups according to the concentration of fructose in the blood of the fetus. Journal of Physiology 132 146-156.

Gu W, Jones CT \& Harding JE 1987 Metabolism of glucose by fetus and placenta of sheep. The effects of normal fluctuations in uterine blood flow. Journal of Developmental Physiology 9 369-389.

Hashizume K, Ishiwata H, Kizaki K, Yamada O, Takahashi T, Imai K, Patel OV, Akagi S, Shimizu M, Takahashi S, Katsuma S, Shiojima S, Hirasawa A, Tsujimoto G, Todoroki J \& Izaike Y 2002 Implantation and placental development in somatic cell clone recipient cows. Cloning and Stem Cells 4 197-209.

Hasler JF, Henderson WB, Hurtgen PJ, Jin ZQ, McCauley AD, Mower SA, Neely B, Shuey LS, Stokes JE \& Trimmer SA 1995 Production, freezing and transfer of bovine IVF embryos and subsequent calving results. Theriogenology 43 141-152.

Hay WW Jr 1995 Regulation of placental metabolism by glucose supply. Reproduction, Fertility, and Development 7 365-375.

Hill JR, Roussel AJ, Cibelli JB, Edwards JF, Hooper NL, Miller MW, Thompson JA, Looney CR, Westhusin ME, Robl JM \& Stice SL 1999 Clinical and pathologic features of cloned calves and fetuses (13 case studies). Theriogenology 51 1451-1465.

Hill JR, Burghardt RC, Jones K, Long CR, Looney CR, Shin T, Spencer TE, Thompson JA, Winger QA \& Westhusin ME 2000 Evidence for 
placental abnormality as the major cause of mortality in first-trimester somatic cell cloned bovine fetuses. Biology of Reproduction 63 1787-1794.

Hill JR, Edwards JF, Sawyer N, Blackwell C \& Cibelli JB 2001 Placental anomalies in a viable cloned calf. Cloning 3 83-88.

Hugget ASG \& Nixon DA 1961 Fructose as a component of the foetal blood in several mammalian species. Nature 1901209.

Jacobsen H, Schmidt M, Holm P, Sangild PT, Greve T \& Callesen H 2000 Ease of calving, blood chemistry, insulin and bovine growth hormone of newborn calves derived from embryos produced in vitro in culture systems with serum and co-culture or with PVA. Theriogenology 54 147-158.

Leutenegger CM, Alluwaimi AM, Smith WL, Perani L \& Cullor JS 2000 Quantitation of bovine cytokine mRNA in milk cells of healthy cattle by real-time TaqMan ${ }^{\circledR}$ polymerase chain reaction. Veterinary Immunology and Immunopathology 77 275-287.

Mayes PA 1993 Intermediate metabolism of fructose. American Journal of Clinical Nutrition 58 754S-765S.

McGowan JE, Aldoretta PW \& Hay WW Jr 1995 Contribution of fructose and lactate produced in placenta to calculation of fetal glucose oxidation rate. American Journal of Physiology 269 E834-E839.

Meznarich HK, Hay WW Jr, Sparks JW, Meschia G \& Battaglia FC 1987 Fructose disposal and oxidation rates in the ovine fetus. Quarterly Journal of Experimental Physiology 72 617-625.

Nixon DA 1963 The transplacental passage of fructose, urea and meso-inositol in the direction from foetus to mother, as demonstrated by perfusion studies in the sheep. Journal of Physiology 166 $351-362$

Perry VEA, Norman ST, Owen JA, Daniel RCW \& Phillips N 1999 Low dietary protein during early pregnancy alters bovine placental development. Animal Reproduction Science 55 13-21.

Prior RL \& Laster DB 1979 Development of the bovine fetus. Journal of Animal Science 48 1546-1553.

Reynolds LP, Ferrell CL, Robertson DA \& Ford SP 1986 Metabolism of the gravid uterus, foetus and utero-placenta at several stages of gestation in cows. Journal of Agricultural Science of Cambridge $106437-444$.

Reynolds LP, Ferrell CL, Robertson DA \& Klindt J 1990 Growth hormone, insulin and glucose concentrations in bovine fetal and maternal plasmas at several stages of gestation. Journal of Animal Science 68 725-733.

Roberts SJ 1986 Gestation period: embryology, fetal membranes and placenta. In Veterinary Obstetrics and Genital Diseases (Theriogenology), pp 38-50. Ed. SJ Roberts. Arbor, MI: Edward Brothers.

Sacks DB 1999 Carbohydrates. In Tietz Textbook of Clinical Chemistry, pp 750-808. Eds CA Burtis \& ER Ashwood. Philadelphia: WB Saunders.

Sangild PT, Schmidt M, Jacobsen H, Fowden AL, Forhead A, Avery B \& Greve T 2000 Blood chemistry, nutrient metabolism, and organ weights in fetal and newborn calves derived from in vitroproduced bovine embryos. Biology of Reproduction 62 1495-1504.

Schlafer DH, Fisher PJ \& Davies CJ 2000 The bovine placenta before and after birth: placental development and function in health and disease. Animal Reproduction Science 60-61 145-160.

Seri I 1998 Regulation of acid-base balance in the fetus and neonate. In Fetal and Neonatal Physiology, pp 1726-1730. Eds RA Polin \& WW Fox. Philadelphia: WB Saunders.

Simmons MA, Battaglia FC \& Meschia G 1979 Placental transfer of glucose. Journal of Developmental Physiology $1227-243$.

Skydsgaard JM 1965 The pathogenesis of hydroallantois bovis. Acta Veterinaria Scandinavica 6 193-207.

Stice SL, Strelchenko NS, Keefer CL \& Matthews L 1996 Pluripotent bovine embryonic cell lines direct embryonic development following nuclear transfer. Biology of Reproduction 54 100-110.

Symonds ME, Budge H, Stephenson T \& McMillen IC 2001 Fetal endocrinology and development - manipulation and adaptation to long-term nutritional and environmental challenges. Reproduction $121853-862$.

Taylor KACC 1995 A colorimetric fructose assay. Applied Biochemistry and Biotechnology 53 215-227.

Torrance SM \& Wittnich C 1994 Blood lactate and acid-base balance in graded neonatal hypoxia: evidence for oxygen-restricted metabolism. Journal of Applied Physiology 77 2318-2324.

Van den Berghe G 1994 Inborn errors of fructose metabolism. Annual Review of Nutrition 14 41-58.

Van Wagtedonk-de Leew AM, Aerts BJG \& den Daas JHG 1998 Abnormal offspring following in vitro production of bovine preimplantation embryos: a field study. 49 883-894.

Van Wagtedonk-de Leew AM, Mullaart E, Roos APW, Merton JS, den Daas JHG, Kemp B \& de Ruigh L 2000 Effects of different reproduction techniques: $\mathrm{Al}, \mathrm{MOET}$ or IVP, on health and welfare of bovine offspring. Theriogenology 53 575-597.

Walker SK, Hartwich KM \& Seamark RF 1996 The production of unusually large offspring following embryo manipulation: concepts and challenges. Theriogenology 45 111-120.

Willadsen SM, Janzen RE, McAlister RJ, Shea BF, Hamilton G \& McDermand D 1991 The viability of late morulae and blastocysts produced by nuclear transplantation in cattle. Theriogenology $\mathbf{3 5}$ $161-170$.

Wintour EM, Laurence BM \& Lingwood BE 1986 Anatomy, physiology and pathology of the amniotic and allantoic compartments. Australian Veterinarian Journal 63 216-221.

Received 4 February 2004

First decision 6 May 2004

Accepted 8 June 2004 